\title{
When Choice is Demotivating: Can One Desire Too Much of a Good Thing?
}

\author{
Sheena S. Iyengar \\ Columbia University
}

Mark R. Lepper

Stanford University

\begin{abstract}
Current psychological theory and research affirm the positive affective and motivational consequences of having personal choice. These findings have led to the popular notion that the more choice, the better-that the human ability to manage, and the human desire for, choice is unlimited. Findings from 3 experimental studies starkly challenge this implicit assumption that having more choices is necessarily more intrinsically motivating than having fewer. These experiments, which were conducted in both field and laboratory settings, show that people are more likely to purchase gourmet jams or chocolates or to undertake optional class essay assignments when offered a limited array of 6 choices rather than a more extensive array of 24 or 30 choices. Moreover, participants actually reported greater subsequent satisfaction with their selections and wrote better essays when their original set of options had been limited. Implications for future research are discussed.
\end{abstract}

Ne quid nimis. (In all things moderation.)

-Publius Terentius Afer (Terence), c. 171 B.C.

It is a common supposition in modern society that the more choices, the better - that the human ability to manage, and the human desire for, choice is infinite. From classic economic theories of free enterprise, to mundane marketing practices that provide customers with entire aisles devoted to potato chips or soft drinks, to important life decisions in which people contemplate alternative career options or multiple investment opportunities, this belief pervades our institutions, norms, and customs. Ice cream parlors compete to offer the most flavors; major fast-food chains urge us to "Have it our way."

Sheena S. Iyengar, Graduate School of Business, Columbia University; Mark R. Lepper, Department of Psychology, Stanford University.

We gratefully acknowledge the cooperation and assistance of Draeger's Grocery Store located in Menlo Park, California, for generously offering their store as a field site for conducting Study 1. Similarly, Study 2 could not have occurred without the cooperation and support of Claude Steele at Stanford University who generously allowed his introductory social psychology course to be used as a forum for conducting this field experiment. Further, we would like to thank the numerous graduate students in the Department of Psychology at Stanford University and undergraduate research assistants who generously dedicated their time and effort to help conduct these studies.

Correspondence concerning this article should be addressed to Sheena S. Iyengar, Columbia University, Graduate School of Business, Uris HallRoom 714, 3022 Broadway, New York, New York 10027-6902, or to Mark R. Lepper, Department of Psychology, Jordan Hall-Building 420, Stanford University, Stanford, California 94305-2130. Electronic mail may be sent to ss957@columbia.edu or lepper@psych.stanford.edu.
On the face of it, this supposition seems well supported by decades of psychological theory and research that has repeatedly demonstrated, across many domains, a link between the provision of choice and increases in intrinsic motivation, perceived control, task performance, and life satisfaction (Deci, 1975, 1981; Deci \& Ryan, 1985; Glass \& Singer, 1972a, 1972b; Langer \& Rodin, 1976; Rotter, 1966; Schulz \& Hanusa, 1978; Taylor, 1989; Taylor \& Brown, 1988). In a typical laboratory study, the intrinsic motivation of participants is compared across two conditions: one in which participants are given a choice among half a dozen possible activities, and a second in which participants are told by an experimenter which specific activity to undertake (Zuckerman, Porac, Lathin, Smith \& Deci, 1978). The recurring empirical finding from these studies is that the provision of choice increases intrinsic motivation and enhances performance on a variety of tasks.

Moreover, the positive consequences of choice are often apparent even in contexts where the choice itself is trivial or incidental (Cordova \& Lepper, 1996; Dember, Galinsky, \& Warm, 1992; Swann \& Pittman, 1977). Indeed, many important theories in social psychology, including attribution theory (e.g., Kelley, 1967, 1973), dissonance theory (e.g., Collins \& Hoyt, 1972; Cooper \& Fazio, 1984; Linder, Cooper, \& Jones, 1967), and reactance theory (e.g., Brehm, 1966), all presume that even purely illusory perceptions of choice will have powerful effects (Langer, 1975; Lefcourt, 1973; Lewin, 1952).

Although prior research has made a compelling case for the psychological benefits of the provision of choice, there remain some potential limitations to this literature. Consider one seemingly trivial, yet potentially important, methodological characteristic of prior studies: that the number of options presented in 
previous experiments was characteristically small, typically between two and six alternatives. It would appear, then, that what prior research has actually shown is that choice among relatively limited alternatives is more beneficial than no choice at all. Presumably, of course, constraints on the number of options offered in past choice studies were imposed primarily for the sake of convenience; however, real-world situations often provide more than a limited selection, sometimes even an overwhelming number of options. What happens when the range of alternatives becomes larger and the differences among options become relatively small?

Certainly, there are cases when even a vast array of choices may still have beneficial effects. Imagine a group of people who arrive at a new restaurant, for example, all hoping to order their personal favorite dishes. Obviously, the more items offered on the menu, the more satisfied these customers will be, on average. More generally, in preference-matching contexts, in which people enter hoping to find some particular product or service they already know themselves to prefer, larger numbers of options should increase the likelihood that they will be successful in their search.

On the other hand, a growing body of research also suggests that people can have difficulty managing complex choices. To begin with, research has shown that as the attractiveness of alternatives rises, individuals experience conflict and as a result tend to defer decision, search for new alternatives, choose the default option, or simply opt not to choose (Dhar, 1997; Shafir, Simonson, \& Tversky, 1993; Shafir \& Tversky, 1992). Furthermore, consumer research suggests that as both the number of options and the information about options increases, people tend to consider fewer choices and to process a smaller fraction of the overall information available regarding their choices (Hauser \& Wernerfelt, 1990).

In fact, studies show that the selection, evaluation, and integration of information are all clearly affected by the available number of options; this suggests that, as the complexity of making choices rises, people tend to simplify their decision-making processes by relying on simple heuristics (Payne, 1982; Payne, Bettman, \& Johnson, 1988, 1993; Timmermans, 1993; Wright, 1975). For instance, a comparison of the decision strategies of people presented with three, six, or nine alternatives revealed that $21 \%$ used an elimination strategy in the case of three options, $31 \%$ used an elimination strategy in the case of six options, and $77 \%$ used an elimination strategy when there were nine options (Timmermans, 1993). The increase in the percentage of participants who used an elimination strategy as the number of alternatives grew was also accompanied by a decrease in the percentage of information used. This sharp decrease in the number of attributes considered as problem complexity increases suggests that information overload may produce a change to a noncompensatory but more efficient decision rule.

The three studies presented in this article, therefore, examine for the first time the possibility that there may be differential motivational consequences of encountering contexts that offer a limited (i.e., psychologically manageable), versus an extensive (i.e., psychologically excessive), number of choices. Specifically, the choice overload hypothesis underlying these studies is that, although the provision of extensive choices may sometimes still be seen as initially desirable, it may also prove unexpectedly demotivating in the end.

In these studies, limited-choice conditions were operationalized as contexts that offered roughly the same number of options (approximately six) as used in past research (e.g., Zuckerman et al., 1978). In comparison, extensive-choice conditions were operationalized as contexts in which participants would have some reasonably large, but not ecologically unusual, number of options.

In addition, to provide a clear test of the choice overload hypothesis, several additional methodological considerations seemed important. On the one hand, to minimize the likelihood of simple preference matching, care was taken to select contexts in which most participants would not already have strong specific preferences. On the other hand, to minimize the potential importance of effortful information search, care was also taken to select tasks for which "right" and "wrong" choices would be subjective, so that the effort involved in making a choice would be largely a function of personal preferences. Finally, across experiments, we sought to examine this hypothesis in both field and laboratory settings. Using these criteria, then, the present studies tested the hypothesis that having a limited and more manageable set of choices may be more intrinsically motivating than having an overly extensive set of choices.

\section{Study 1}

In this first field experiment, consumers shopping at an upscale grocery store encountered a tasting booth that displayed either a limited (6) or an extensive (24) selection of different flavors of jam. The two dependent measures of customers' motivation were their initial attraction to the tasting booth and their subsequent purchasing behavior.

\section{Method}

\section{Participants and Experimental Site}

Study 1 involved a field experiment that examined the motivational consequences of limited versus extensive choice in an upscale grocery store (Draeger's Supermarket) located in Menlo Park, California. This grocery store is of particular interest because its salient distinguishing feature is the extraordinary selection it offers, especially when compared with large grocery chains. For instance, Draeger's offers roughly 250 different varieties of mustard, 75 different varieties of olive oil, and over 300 varieties of jam. In addition, because of the regular presence of tasting booths at this store, shoppers are frequently offered sample tastes of the enormous array of available products. As a result, this store provided a particularly conducive environment in which a naturalistic experiment that used tasting booths could be conducted.

On two consecutive Saturdays, neither of which fell on a long holiday weekend, a tasting booth was set up inside the grocery store. Over the course of these two 5-hr experimental periods, the behavior of approximately 754 shoppers was observed. Among the 386 customers present in the store during the hours when the extensive-choice booth was displayed, only 242 actually encountered the display. Among the 368 customers present in the store during the hours when the limited-choice booth was displayed, only 260 actually encountered the display. By observation, the customers who stopped at the booth were typically middle-aged Caucasians; approximately $62 \%$ of these customers were women and $38 \%$ were men.

\section{Product Selection}

Exotic jams. Before the study, the number of brands and selections within a number of product categories were carefully catalogued. On the basis of the following criteria, the product selected as the experimental 
stimulus was Wilkin \& Sons (Purveyors to Her Majesty the Queen) jams. To control for potential differences that might arise from different types of packaging or advertising, it was necessary to find one brand for which there was a sufficiently large variety to constitute an extensive-choice condition. (In total, Wilkin \& Sons has 28 varieties of jams.) In addition, careful attention was given to selecting a product with which most consumers would be familiar, yet not so familiar that preferences would already be firmly established. Hence, to ensure that potential customers would not just reach for the more traditional flavors such as strawberry and raspberry, these common flavors were removed from the set of 28 , leaving a choice set of 24 more exotic flavors. Finally, because the dependent measure involved purchasing behavior, a relatively inexpensive product needed to be chosen. The price of Wilkin \& Sons jams ranged from 4 to 6 dollars.

Jam preferences survey. To ensure that the limited-choice set consisted of neither the most preferred nor the least preferred jam flavors, a preliminary survey of 30 Stanford undergraduates examined individual preferences for the 24 flavors of jam. These students were provided a list of the 24 exotic jam flavors and were asked, "Please read the following list of jams. Put a star next to the two best-sounding jams, in your opinion. Put a check mark next to two good but not excellent-sounding jams, and an $X$ next to the two worst sounding jams." On the basis of this preliminary survey, kiwi and peach jams were selected to represent the two most preferred jams, black cherry and three-fruits marmalade were selected to represent the moderately tasty jams, and lemon curd and red currant were selected to represent the least preferred jams.

\section{Procedure}

Two research assistants, dressed as store employees, invited passing customers to "come try our Wilkin and Sons jams." Shoppers encountered one of two displays. On the table were either 6 (limited-choice condition) or 24 (extensive-choice condition) different jams. On each of two Saturdays, the displays were rotated hourly; the hours of the displays were counterbalanced across days to minimize any day or time-of-day effects.

Initial testing. Consumers were allowed to taste as many jams as they wished. All consumers who approached the table received a coupon for a \$1-discount off the purchase of any Wilkin \& Sons jam. Afterwards, any shoppers who wished to purchase the jam needed to go to the relevant jam shelf, select the jam of their choice, and then purchase the item at the store's main cash registers. As a result, regardless of the tasting-booth display encountered by each customer, all potential buyers of Wilkin \& Sons products necessarily encountered the entire display of flavors.

An inconspicuous observer recorded the number of customers who approached the table, as well as the number of passers-by who did not stop. A second observer, also unobtrusive, made educated guesses about the ethnicity, age, and gender of each customer who did stop at the tasting booth.

In addition, a random sample of solicitations was tape-recorded and later presented to two independent raters, unaware of both the conditions and hypotheses of the study, who rated each solicitation on a 1-5 Likert scale of "friendliness" ranging from not at all friendly to very friendly. Overall, the average friendliness score was high $(M=4.5)$, and the correlation between the raters was high, $r=.90, p<.0001$. Subsequent analyses on these scores showed that the solicitations did not vary according to condition, $F(1,99)=.86, n s$.

Subsequent purchasing. On the bottom left-hand corner of each discount coupon was a code indicating the condition assignment and gender of each consumer. Other numbers and letters surrounded these codes to lead customers to believe that the code represented a coupon scan number. Coupons could be redeemed over a period of 1 week.

\section{Results}

The central aim of Study 1 was to examine whether the number of options displayed affected consumers' initial attraction to or subsequent purchase of the displayed product. As noted, more women than men stopped at the booth; however, there were no gender differences by condition, either for initial attraction or for subsequent purchasing behavior.

\section{Initial Attractiveness of Selections}

To what extent does having extensive choice initially seem desirable? Of the 242 customers who passed the extensiveselection display of jams, $60 \%$ (145) actually stopped at the booth. In contrast, of the 260 customers who passed the limited-selection display of jams, only $40 \%$ (104) stopped. Thus, consumers who encountered the extensive-choice condition were more attracted to the booth than consumers exposed to the limited-choice condition, suggesting that the variety provided in the extensive-choice condition was initially more attractive, $\chi^{2}(1, N=502)=19.89, p<$ $.001 .^{1}$

One might imagine that consumers who encountered 24 different jams would sample more flavors than would those who encountered 6 different varieties. In fact, however, there were no significant differences, $F(1,245)=0.83, n s$; consumers in the extensive-choice condition sampled an average of $1.50 \mathrm{jams}$ (range $=1-2$ ), whereas consumers in the limited-choice condition sampled an average of 1.38 jams (range $=1-2$ ).

\section{Subsequent Purchasing Behavior}

Is the initial attractiveness of extensive choice also reflected in subsequent purchasing behavior? Our findings suggest not: Nearly $30 \%$ ( 31 ) of the consumers in the limited-choice condition subsequently purchased a jar of Wilkin \& Sons jam; in contrast, only $3 \%$ (4) of the consumers in the extensive-choice condition did so, $\chi^{2}(1$, $N=249)=32.34, p<.0001$. Thus, consumers initially exposed to limited choices proved considerably more likely to purchase the product than consumers who had initially encountered a much larger set of options.

\section{Discussion}

These findings are striking. Certainly, they appear to challenge a fundamental assumption underlying classic psychological theories of human motivation and economic theories of rationalchoice-that having more, rather than fewer, choices is necessarily more desirable and intrinsically motivating. The findings from this study show that an extensive array of options can at first seem highly appealing to consumers, yet can reduce their subsequent motivation to purchase the product. Even though consumers presumably shop at this particular store in part because of the large number of selections available, having "too much" choice seems nonetheless to have hampered their later motivation to buy.

There are, however, several potential limitations to this initial field experiment. To begin with, it is possible that consumers in the limited-choice condition believed that there was something special about the specific six jams displayed, especially after they became

\footnotetext{
${ }^{1}$ In keeping with current guidelines, because the cell sizes in the present studies were substantial (Siegel, 1956) and because there were more than 5 times as many subjects as there were cells (Delucchi, 1983), it was not deemed necessary to perform a correction for continuity.
} 
aware of the multitude of other options available on the shelf. Such a belief could have made the limited-choice consumers more prone to purchase jam. Consequently, it is worth considering whether the pattern of results would be altered if the limited-choice condition were operationalized such that participants were not aware of the multitude of other options potentially available.

In addition, the contrasting displays of jam may have invited motivationally differing consumer groups. Although the display of 24 jams may have aroused the curiosity of otherwise uninterested passers-by, the display of 6 jams may have appealed to store customers who were more serious about the purchasing of jam. To rule out this possibility, it was necessary to examine the motivational consequences of limited versus extensive choices with a sample of participants who were not given the opportunity to self-select their condition assignment.

Finally, since consumers in both conditions sampled no more than two jam flavors, it is possible that the consumers in the extensive-choice condition felt that they did not have sufficient time to determine their preferences. Although consumers in both conditions were allowed the freedom to peruse and to sample as many of the displayed flavors as they wished, social pressure or time constraints may have prevented them from taking full advantage of this opportunity. Thus, one might question whether the obtained differences in motivation would be eliminated if participants in both conditions were given the opportunity to peruse their options in an unconstrained, nonpublic context.

Study 2 endeavored to address these concerns and to generalize the findings from Study 1 to an educational setting, in which measures of actual performance, as well as choice, could be observed. Thus, in Study 2, participants in the limited-choice condition were not aware of any options beyond those in the limited-choice set. Similarly, careful attention was given to choosing a task that enabled participants to spend as much time as they wished in perusing their choices. Moreover, unlike Study 1, Study 2 employed a yoked design; the limited-choice set was rotated such that for every item encountered by an extensivechoice participant, there was a limited-choice participant who had encountered the same item.

\section{Study 2}

In Study 2, students in an introductory social psychology class were given the opportunity to write a two-page essay as an extracredit assignment. Students were given either 6 or 30 potential essay topics on which they could choose to write. Intrinsic motivation was assessed by comparing the percentage of students who completed the assignment across the two conditions and the quality of the essays written in each condition.

\section{Method}

\section{Participants}

One hundred ninety-seven students in an introductory social psychology class at Stanford University served as the participants in this study. The class included 116 women and 81 men. In addition to attending biweekly lectures, all students were required to attend smaller weekly discussion sections led by five graduate student teaching assistants. The students were divided into 10 discussion sections; each of the five teaching assistants led 2 sections. Sections included anywhere from 8 to 26 students. Four students ultimately dropped the class and were therefore excluded from the analysis.

\section{Procedures}

As part of the course, all students were required to watch the movie, "Twelve Angry Men." Related to this requirement, an extra-credit assignment was offered, and it was the administration of this extra-credit opportunity that provided the context for a naturalistic experiment.

Before Thanksgiving week, extra-credit assignments were distributed to the students. All assignments included the following instructions:

Instead of having section next week, all students will be required to watch a movie being shown in room $\mathbf{4 0}$ on Monday, November 25 , between 7-9 PM. After watching the movie, you can obtain two extra credit points on your next midterm examination by writing a response paper to the movie. The following is a list of possible questions you can write about. Papers should be approximately one to two pages typed, double spaced, and are due Tuesday, December 3 , in class. If you choose to do this assignment, you must circle the paper topic and attach this page to your response paper.

After reading these instructions, students found themselves confronted by either 6 different essay topics (limited-choice condition) or 30 different essay topics (extensive-choice condition). All essay questions dealt with topics related to the material covered in the course. Careful attention was given to selecting essay topics that were comparable in difficulty, and analyses of performance revealed no differences as a function of the specific topic chosen.

In all, there were six different versions of the extra-credit assignment. In addition to the 30-topic assignment, five versions of the 6-topic assignment were created, such that all of the items from the list of 30 were counterbalanced across the five limited-choice assignments.

Students were first informed of the movie requirement during the weekly section meeting before Thanksgiving week. To minimize the possibility that students would notice the different versions, assignments were handed out in the section meetings rather than in class lectures. At this time, the teaching assistants distributed these assignments, with an identical verbal description, reinforcing the information about the opportunity for students to gain two extra points on their next midterm. On no occasion were students led to believe that their essays would be graded. On the contrary, they were explicitly told that their performance on the assignment was irrelevant to the receipt of the two points.

Because each of the five teaching assistants administered two separate sections, one of these two sections was assigned to the limited-choice condition and the other was assigned to the extensive-choice condition. In this way, five sections of students received six essay topics and five sections of students received thirty. Because the number of students per section varied, it was not possible to assign equal numbers of students to the two conditions. As a result, 70 students were assigned to the limitedchoice condition, whereas 123 students were assigned to the extensivechoice condition. No differences were found across the five teaching assistants in terms of assignment completion; students assigned to one teaching assistant were just as likely to do the extra-credit assignment as students assigned to another teaching assistant.

\section{Dependent Measures}

Two measures assessed students' subsequent motivation in the two conditions. The first was the percentage of participants who chose to write an essay. The second was the quality of the essays produced.

As previously indicated, the students were told that their performance on these extra-credit assignments would have no impact on their class grades. Nevertheless, it was of interest to determine whether the number of alternatives available might also affect performance quality. Accordingly, 
two graduate students, unaware of both the participants' choice conditions and the hypotheses of this experiment, graded each of the response papers for both content and form using two 10-point scales, which ranged from "extremely poor" to "excellent."

When grading for content, two factors were taken into consideration. The first was the accurate depiction and appropriate use of socialpsychological concepts. The second was the use of clear examples from the film that related and mapped onto the different social-psychological processes being discussed. The inter-rater correlation for content scores was $r=.70, p<.0001$. The form score similarly assessed students' facility on two dimensions. First, each paper was judged on whether it had clear structure (e.g., "Did the introductory paragraph define a hypothesis?"). Second, the papers were evaluated on technical proficiency-spelling, grammar, and the like. The inter-rater correlation for form scores was $r=$ $.89, p<.0001$. Because there was considerable agreement across the two graders on both content and form, their ratings were averaged, yielding one content and one form score per student.

\section{Results}

\section{Preliminary Analyses}

The central point of interest in Study 2 lay, once again, in the comparison of participants' responses across the two experimental conditions of limited versus extensive choice. Because preliminary analyses showed no differences as a function of gender and no interactions between gender and condition on either measure, the data were collapsed across this factor.

\section{Assignment Completion}

Did the number of choices provided on the instruction sheet actually influence the percentage of students who completed the assignment? Overall, 65\% (126) of the students chose to do the assignment. There was, however, a significant effect of condition, $\chi^{2}(1, N=193)=3.93, p<.05$. Of the 70 students assigned to the limited-choice condition, $74 \%$ turned in the assignment. In contrast, of the 123 students assigned to the extensive-choice condition, only $60 \%$ chose to complete the assignment.

\section{Quality of Essays}

Were these differences in students' willingness to write an essay also reflected in differences in the quality of these essays? For content, there was a main effect for condition, $F(1,124)=4.18$, $p<.05$. On average, students assigned to the limited-choice condition performed slightly, although significantly, better $(M=8.13, S D=0.95)$ than those assigned to the extensive-choice condition $(M=7.79, S D=0.91)$. A similar main effect was found for form, $F(1,124)=4.64, p<.03$. On average, students in the limited-choice condition scored higher $(M=8.04, S D=1.33)$ than students in the extensive-choice condition $(M=7.59$, $S D=1.02$ ).

Because measures of content and form proved significantly correlated $(r=.52, p<.0001)$, content and form grades were also averaged to give one overall grade. The condition effect was also significant for this overall measure, $F(1,124)=5.65, p<.02$, with students in the limited-choice condition receiving higher grades $(M=8.09, S D=1.05)$ than those in the extensive-choice condition $(M=7.69, S D=0.82)$.
One might ask whether the observed differences in motivation or performance could somehow have been driven by differences in students' prior performance in the class. There were, however, no differences in class midterm performance by condition among the students who completed the extra-credit assignments, nor were there differences in midterm performance between those who subsequently did or did not choose to do the assignment.

\section{Discussion}

The findings from Study 2 both confirm and expand on the findings from Study 1. The results from both studies suggest that the provision of extensive choices does not necessarily lead to enhanced motivation when compared with contexts that offer a limited array of choices. Quite the opposite seems to be the case. In both studies, people actually seemed to prefer to exercise their opportunity to choose in contexts where their choices were limited, and, in Study 2, they even performed better in such limited-choice contexts.

Particularly counterintuitive, from the perspective of traditional models, is the finding that the same choice selected from a limitedchoice set can lead to better performance than if the same option had been selected from an extensive-choice set. Interestingly, in contrast to prior studies, the measure of performance in the present experiment was designed to reflect intrinsic motivation. Because none of the participants thought that their essays would be evaluated, the quality of the paper they wrote should have been primarily a function of their personal interest and motivation.

Thus, the results of Studies 1 and 2 support the hypothesis that extensive-choice contexts may be initially more appealing but are subsequently more likely to hamper people's intrinsic motivation. Although these field experiments provide compelling empirical evidence to support this hypothesis, they shed little light on the mediating mechanisms underlying choice overload. What, then, are the processes that produce the decreases in subsequent motivation exhibited in contexts that offer extensive choices?

One possibility is that people encountering overly extensive choices use a choice-making heuristic that necessarily leads them to feel less committed to exercising their preferences. Previous research has argued that limited-choice contexts invite people to engage in rational optimization-to try to decide which option in a set is the single best one for them. By contrast, choosers in extensive-choice contexts may endeavor to balance the tradeoffs between accuracy and effort, adopting simplifying heuristic strategies that are much more selective in their use of available information (Christensen-Szalanski, 1978, 1980; Payne et al., 1988, 1993). Consequently, extensive-choice contexts may invite people merely to "satisfice"- to stop when they find any choice that seems acceptable (Mills, Meltzer, \& Clark, 1977; Simon, 1955, 1956). In other words, when people have "too many" options to consider, they simply strive to end the choice-making ordeal by finding a choice that is merely satisfactory, rather than optimal. Doing otherwise would demand more effort than seems justified by the prospective increase in utility or satisfaction. Hence, one

\footnotetext{
${ }^{2}$ No actual grade proved lower than a "5," and grades were not restricted to whole numbers.
} 
might predict that people who encounter extensive choices should report making a less informed decision and should be more likely to opt for a default choice (Hauser \& Wernerfelt, 1990; Payne, 1982; Shafir et al., 1993; Shafir \& Tversky, 1992). Similarly, choosers opting to satisfice in extensive-choice contexts should also report being less confident of their choices and less likely to expect to be satisfied with their particular choices.

A contrasting possibility is that choosers in extensive-choice contexts may actually feel more committed to the choice-making process; that is, that they may feel more responsible for the choices they make because of the multitude of options available. These enhanced feelings of responsibility, in turn, may inhibit choosers from exercising their choices, out of fear of later regret. In other words, choice-makers in extensive-choice contexts might feel more responsible for their choices given the potential opportunity of finding the very best option, but their inability to invest the requisite time and effort in seeking the so-called best option may heighten their experience of regret with the options they have chosen. If so, choosers in extensive-choice contexts should perceive the choice-making process to be more enjoyable given all the possibilities available. They should at the same time, however, find it more difficult and frustrating given the potentially overwhelming and confusing amount of information to be considered.

Study 3, therefore, sought both to provide an instantiation of the phenomenon of choice overload in a controlled laboratory setting and to supplement the findings from the last two studies by including a number of measures designed to test the two opposing hypotheses outlined above. To test the first hypothesis-that people encountering extensive choices tend to use a satisficing heuristic, whereas people encountering limited choices tend to use an optimizing heuristic-Study 3 examined choosers' expectations regarding the choices they had made.

As before, after participants had encountered either a limited array or an extensive array of options in this study, they were asked to make a choice. Unlike the prior two studies, however, before being given the opportunity to sample the selection they had made, choosers' expectations about this choice were assessed. Participants provided predictions about how satisfied they would be with their stated preference--whether they expected the choice they made to be merely "satisfactory" or "among the best." Participants also indicated whether they had chosen a default option and reported how well-informed they felt about the choice they had made. To test the second hypothesis-that people in extensivechoice contexts feel more responsible for the choices they makeseveral affect items were added to Study 3 . Specifically, after making their choices, but before sampling their choices, participants were asked to provide ratings of their enjoyment, difficulty, and frustration during the choice-making process. Later, after sampling their choices, they provided ratings of satisfaction and regret.

Finally, Study 3 also included a no-choice control condition. Inclusion of this third group allowed us to examine whether differences between the limited- and extensive-choice groups were the result of increases in motivation among limited-choice participants and/or decreases in motivation among extensive-choice participants.

\section{Study 3}

In Study 3, participants initially made a selection from either a limited array or an extensive array of chocolates. Subsequently, participants in the experimental groups sampled the chocolate of their choosing, whereas participants in the control group sampled a chocolate that was chosen for them. Participants' initial satisfaction with the choosing process, their expectations concerning the choices they had made, their subsequent satisfaction with their sampled chocolates, and their later purchasing behavior served as the four main dependent measures in this study.

Conceptually, then, the design of Study 3 involved three groups: limited choice, extensive choice, and a no-choice control condition. Because it seemed important to control for the number of alternatives presented across the choice and no-choice conditions, half of the participants in the no-choice conditions were shown the same 6 choices as participants in the limited-choice condition, whereas the other half were shown the full array of 30 choices, as were participants in the extensive-choice condition.

Because the choice-condition participants and their no-choice counterparts were treated identically up through the administration of the first set of dependent measures, analyses of these measures will involve only comparisons of those exposed to limited displays versus those exposed to extensive displays. Once participants had been given either their own selection or an arbitrarily assigned chocolate to taste, however, comparisons of limited-choice and extensive-choice participants to those in the no-choice control condition then became relevant.

\section{Method}

\section{Participants}

One hundred thirty-four students from Columbia University were randomly assigned to one of three conditions. There were 33 participants in the limited-choice condition, 34 participants in the extensive-choice condition, and 67 participants in the no-choice condition. This sample included $63 \%$ women and $37 \%$ men. The ethnic distribution of the participants was 55\% Caucasian, 25\% Asian, 5\% Latino, 4\% African American, and $11 \%$ Other.

To eliminate any participant who might have an aversion to chocolate, all potential participants were prescreened on the basis of two questions. First, all potential participants were asked, "Do you like chocolate?" Only those who responded "yes" to this item were then recruited to be participants in this study. Second, participants were asked, "How often do you eat Godiva chocolates?" Responses were coded as "never," "occasionally," or "frequently." Because it was believed that high familiarity with Godiva flavors and varieties might confound a participant's behavior within this study, only those participants who responded "never" or "occasionally" were recruited for this study. Approximately $92 \%$ of all potential participants met these two criteria and were invited to be part of the study.

\section{Instruments}

Decision-making measures. A questionnaire was designed to examine participants' affective responses to the choice-making process and their expectations after making a choice. To prevent participants' responses from being biased by the outcome of their choice, we asked them to complete the questionnaire after they had chosen which chocolates they wished to sample, but before they had been given the opportunity to sample their choice. All items called for ratings on a Likert scale ranging from 1 (not at all) to 7 (extremely). 
To test the hypothesis that people encountering extensive choices can experience the choice-making process as both enjoyable and overwhelming, the questionnaire examined participants' perceptions of the choicemaking process. Specifically, participants were asked about the extent to which they felt the choice-making process had been enjoyable ("How much did you enjoy making the choice?"), difficult ("Did you find it difficult to make your decision of which chocolate to pick?"), or frustrating ("How frustrated did you feel when making the choice?'). They also predicted how satisfied they would be if they had the opportunity to sample their chosen chocolate ("How satisfied do you think you will be if you sample this chocolate?").

To evaluate whether people encountering limited choices are more likely to optimize (i.e., to seek the very best option) whereas people encountering extensive choices are more likely to satisfice (i.e., to accept any satisfactory option), two items were created to examine participants' expectations regarding their choices. To measure perceived satisficing, we asked participants to provide ratings for, "How confident are you that this chocolate will satisfy you?" To examine perceived optimizing, we asked "How confident are you that this chocolate will be among the best you've ever had?" Similarly, to evaluate whether people in an extensive-choice context feel less informed and are therefore more prone to choose a default option, we also asked participants, "Do you feel that you made a well-informed decision on the chocolate you picked?" and, "Is this a chocolate that you would normally pick?"

Sample-satisfaction measures. The satisfaction measures were designed to inquire about participants' overall satisfaction with their sampled chocolates. Specifically, these questions assessed participants' actual satisfaction with the chocolate they had consumed, their regrets about the chocolate they had tasted, and their satisfaction with the number of choices they had been given. Experimental participants reported their satisfaction with their chosen samples, of course, whereas control participants reported their satisfaction with a chocolate that had been chosen for them.

To test the hypothesis that participants exposed to extensive choices would be less satisfied with their choices than participants exposed to limited choices, three items examined participants' satisfaction with their sampled chocolates: "How satisfied were you with the chocolate you tasted?", "How much did you enjoy the sample you tasted?", and, "How tasty was the chocolate you sampled?" All responses were given on Likert scales, ranging from 1 (not at all) to 7 (extremely).

Similarly, to test whether any potential decrease in satisfaction among people encountering overly extensive choices would be accompanied by an increase in regret, two items were included to measure regret: "How much do you regret eating the chocolate you tasted?" and "Do you think that there were chocolates on the table that tasted much better?" Both items were answered on 7-point Likert scales, ranging from 1 (no, not at all) to 7 (yes, completely).

Because one can only infer through behavioral measures in Studies 1 and 2 whether 30 or 24 choices actually constituted an overly extensive choice set, Study 3 included a manipulation check in which participants were asked their perceptions about the number of choices provided. Specifically, participants were asked: "When initially given the task to pick a chocolate from the display, do you think the selection should have included more kinds of chocolates?" Responses were given on a 7-point Likert scale, with 1 being, I felt that I had too few to choose from, 4 being, I had the right number of choices to choose from, and 7 being, No, I had too many to choose from.

Demographic measures. At the conclusion of the experiment, all participants completed a brief demographics questionnaire. This questionnaire inquired about participants' age, ethnicity, gender, and affiliation with Columbia University.

\section{Experimental Procedures}

As participants entered the laboratory, the experimenter directed them to sit at a round table on which there was one of two different displays of chocolates. In the limited-choice display, participants encountered one row of 6 different flavors of Godiva chocolates; in the extensive-choice display, participants encountered 30 different chocolates, arranged in five rows of 6. Next to each chocolate was a label indicating its "official," Godiva name (e.g., "Grand Marnier Truffle"). When designating the composition of the five rows, careful attention was given to ensuring that similar flavors were not in the same row (e.g., a Strawberry Cordial would not be assigned to the same group as the Raspberry Cordial). In those conditions in which participants encountered only six chocolates, the five groups were rotated such that for every chocolate encountered in the extensive-choice display there was a possibility of the same chocolate being encountered in the limited-choice display.

The experimenter gave participants the following cover story for the study: "We're doing a marketing research study that examines how people select chocolates. What I would like you to do is take a look at the names of the chocolates and the chocolates themselves, and tell me which one you would buy for yourself." All participants then proceeded to choose the chocolate they would wish to have.

Because prior research suggests that people making a choice among four alternatives sometimes take less time than people making a selection between two (Hendrick, Mills, \& Kiesler, 1968; Kiesler, 1966), the amount of time spent deciding which chocolate to sample was also recorded in this study. Once the participants pointed to a chocolate, they were asked to complete the decision-making measures described above.

Next, participants encountered the manipulation of choice. In the two choice conditions, the experimenter offered the participants the opportunity to sample the chocolate they had chosen. In contrast, in the no-choice condition, the participants were not permitted to sample the chocolate they had chosen but were instead told, "We have some sample chocolates that have been chosen for you at random. These are [e.g.,] 'Milk Chocolate Truffles'." The experimenter then opened a box containing eight identical chocolates, which were not of the participants' choosing, and asked the participants to take one. As in prior studies (Zuckerman et al., 1978), we used a yoked design, so that the same chocolates chosen by participants in the choice conditions were the ones offered to participants in the no-choice condition.

After sampling the chocolate, participants completed the sample satisfaction measures and the demographics questionnaire described above. Next, the experimenter led the participant to believe that the experiment had concluded, saying, "Thanks. We appreciate your time. You can go see the manager for your compensation in room three."

In the payment room, a second experimenter, unaware of the condition assignments, greeted the participants. This experimenter offered the subject a choice of receiving a payment of either 5 dollars or a box containing four Godiva chocolates ordinarily priced at 5 dollars: "As you know, your compensation is five dollars for being in the study. You can choose between getting five dollars in cash or a box of Godiva chocolates that is worth five dollars. Which one would you like for participating in the survey?" Boxes bearing the emblem of Godiva were visible to the participants as they walked into the room. The number of participants who opted for the box of chocolates constituted the final dependent measure.

One potential problem with these experimental procedures is that although the first experimenters were unaware of the hypotheses underlying the study, they were necessarily aware of the experimental manipulations. As a result, one might reasonably wonder whether the experimenters might vary their behavior across conditions. Therefore, all experimental sessions were videotaped, and 40 sessions ( 10 from each choice condition and 20 from the no-choice condition) were randomly selected for coding by external raters. Two raters unaware of the hypotheses and the experimental manipulations rated the friendliness of the two experimenters across the forty sessions on a 5-point Likert scale. There was considerable agreement across the two raters $(r=.69, p<.0001)$, and their responses were therefore averaged. This average friendliness score $(M=2.86, S D=0.78)$ 
did not vary by condition, $F(2,36)=.01, n s$, and there were no interactions between condition and experimenter, $F(2,36)=.22$, ns.

\section{Results}

\section{Preliminary Analyses}

Our primary aim in Study 3 was to examine differences in satisfaction, purchasing behavior, and related measures across limited-choice, extensive-choice, and no-choice conditions. Before turning to these central issues, however, we first examined the effects of gender and ethnicity on these various measures. No significant differences were observed on any of the dependent variables as a function of these factors. Nor were there any significant interactions between these two factors and experimental conditions. Hence, the data were collapsed across these demographic variables. ${ }^{3}$

Finally, preliminary analyses also provided an empirical examination of two key presumptions underlying our main analyses. As should be expected, for those measures obtained before the introduction of the choice manipulation, there were no significant interactions between the size of the choice set and participants' later receipt of their own selection or an arbitrary alternative. Similarly, as predicted, there were no significant differences on measures obtained after the choice manipulation between nochoice participants previously exposed to a limited versus an extensive set of available alternatives. Data for the relevant measures were therefore collapsed, as appropriate, across these factors.

\section{Manipulation Checks}

Choosing time. As one might assume, the amount of time spent deciding which chocolate to sample varied significantly by condition, $F(1,131)=77.02, p<.0001$. Contrary to some prior findings (Hendrick et al., 1968; Kiesler, 1966), participants spent significantly more time (in seconds) deciding which chocolate to sample when there were 30 chocolates $(M=24.36, S D=12.99)$ than they did when there were only $\operatorname{six}(M=8.91, S D=6.02)$. However, it should be noted that, unlike this study, previous studies only compared choosing times across much smaller choice sets of two versus four alternatives.

Perception of choices. Similarly, we examined participants' responses to the question concerning whether they felt the number of choices available was too few, just right, or too many. Here again, there was a significant effect for the number of options presented, $F(1,132)=43.68, p<.0001$. Participants who encountered 30 chocolates reported feeling that they had been given "too many" ( $M=4.88, S D=1.20)$, whereas participants who encountered 6 chocolates reported feeling that the number of alternatives was "about right" $(M=3.61, S D=1.01)$. These data provide direct evidence for our assumption that 30 chocolates would seem an overly extensive choice set.

\section{Decision-Making Measures}

Satisficing versus optimizing. Were participants in the extensive-choice condition more apt to satisfice, and were participants in the limited-choice condition more apt to optimize? We find no empirical evidence to support such a hypothesis. Contrary to prior predictions (Mills et al., 1977), participants' confidence that they had chosen a satisfactory chocolate versus one of the very best chocolates did not vary as a function of the number of chocolates displayed. The results revealed no differences by condition for questions regarding goals of either satisficing, $F(1$, $94)=0.15, n s$, or optimizing, $F(1,94)=0.09$, ns. Instead, a within-subject analysis of variance (ANOVA) suggested that both the limited- and extensive-choice participants were predictably more confident that their chocolate selection would satisfy them ( $M=5.67, S D=1.21$ ) than that it would be among the best they had ever had $(M=4.16, S D=1.59), F(1,190)=54.75, p<$ .0001 .

Nor were there any differences in anticipated satisfaction. Results indicate that baseline predictions of likely satisfaction did not vary by condition, $F(1,132)=0.61, n s$, suggesting that participants did not perceive the number of available alternatives to be an important variable in their expected satisfaction with their choices.

In addition, we observed no differences by condition in participants' reports of how informed they felt about their choices or in their tendency to choose default options. Both extensive-choice and limited-choice participants reported being moderately well informed $(M=4.55, S D=1.39), F(1,132)=0.14, n s$. Likewise, there were no differences in participants' responses to the question of whether they chose a chocolate that they would normally pick, $F(1,132)=0.24, n s$.

Desirability of choosing. Is it possible for people to experience extensive choices as being both more enjoyable and more overwhelming? Consistent with the findings of Study 1, participants encountering the extensive options $(M=6.02, S D=0.75)$ reported enjoying the decision-making process significantly more than participants who encountered limited options $(M=4.72$, $S D=1.36), F(1,132)=47.01, p<.0001$. Yet, participants offered extensive choices $(M=4.45, S D=1.79)$ also reported finding the decision-making process to be more difficult than did participants offered more limited choices $(M=3.30, S D=1.49)$, $F(1,132)=16.38, p<.0001$. Likewise, extensive-choice participants $(M=3.10, S D=1.77)$ also reported finding the decisionmaking process to be more frustrating than did limited-choice participants $(M=2.24, S D=1.72), F(1,123)=7.61, p<.007$.

Interestingly, there was no significant correlation between the extent to which participants reported enjoying decision-making and the extent to which they found the decision process to be difficult $(r=.11, n s)$ or frustrating $(r=.11, n s)$. How difficult participants found the decision-making process, however, was correlated with the extent to which they found the process to be frustrating ( $r=.36, p<.0001$ ). Thus, it appears that people can indeed find choosing among too many alternatives to be both enjoyable and overwhelming.

\section{Subsequent Satisfaction}

Five questions assessed participants' actual subsequent satisfaction with the particular sample chocolate they were given to taste.

\footnotetext{
${ }^{3}$ Preliminary analyses also asked whether certain chocolates were more preferred than the rest. While no chocolate was universally chosen, there were four chocolates that were never selected. An examination of the frequency distribution reveals that none of the thirty chocolates was selected more than $12.7 \%$ of the time and that the specific choices did not differ by condition.
} 
Three of these items (i.e., tastiness, enjoyment, and satisfaction) assessed subjective enjoyment directly. Because these questions proved significantly correlated with one another (average $r=.62$, $p<.0001$ ) and the pattern of results was similar across the three, a composite enjoyment measure was derived by averaging across these three items for each participant. Two other items assessed participants' feelings of regret about the chocolate they had tasted. These two items also proved significantly correlated $(r=.41, p<$ .0001 ) and were combined into a composite regret measure. Finally, because these two composite measures (i.e., "enjoyment" and "regret") proved to be highly related $(r=-.55, p<.0001)$, a single overall sample-satisfaction score was created for each participant by averaging these components (with regret scores, of course, being coded negatively). It should be noted that the three items that constitute the satisfaction measure were converted into $z$ scores before averaging, as were the two items constituting the regret measure.

A one-way ANOVA on these overall satisfaction scores yielded significant differences among conditions, as in the prior studies, $F(1,122)=28.02, p<.0001$. Tukey comparisons further showed that, in keeping with the results from Studies 1 and 2, participants in the limited-choice condition were significantly more satisfied $(M=6.28, S D=0.54)$ with their sampled chocolates than were participants in the extensive-choice condition $(M=5.46$, $S D=0.82$ ). Tukey comparisons further revealed that on this measure, participants in both choice groups reported themselves to be more satisfied with their chosen chocolates than did no-choice participants $(M=4.92, S D=0.98)$, who had been given samples of chocolates they had not selected.

\section{Purchasing Behavior}

Finally, as in the previous studies, we also examined the effects of limited versus extensive choices on participants' ultimate purchasing behavior. Once again, the results demonstrated the significant advantages of a relatively small choice set, $\chi^{2}(2, N=$ $134)=21.84, p<.0001$. In particular, participants in the limitedchoice condition $(48 \%)$ were significantly more likely to choose chocolates as compensation, as compared with participants in both the extensive-choice condition $(12 \%), \chi^{2}(1, N=67)=10.78, p<$ .001 , and the no-choice condition $(10 \%), \chi^{2}(1, N=100)=18.06$, $p<.0001$, which, on this behavioral measure, clearly did not differ from one another.

\section{General Discussion}

In 1830, Alexis de Tocqueville commented that, "In America I have seen the freest and best educated of men in circumstances the happiest to be found in the world; yet it seemed to me that a cloud habitually hung on their brow, and they seemed serious and almost sad even in their pleasures" (p. 536). More than 100 years later, we are confronted by an empirical instantiation of what some have referred to as "the tyranny of choice" (Schwartz, 2000).

The three studies described in this report demonstrate for the first time the possibility that, although having more choices might appear desirable, it may sometimes have detrimental consequences for human motivation. Studies 1, 2, and 3 provide compelling empirical evidence that the provision of extensive choices, though initially appealing to choice-makers, may nonetheless undermine choosers' subsequent satisfaction and motivation. Study 1 showed that although more consumers were attracted to a tasting booth when the display included 24 flavors of jam rather than 6 , consumers were subsequently much more likely to purchase jam if they had encountered the display of only 6 jams. Study 2 revealed that students in an introductory college level course were more likely to write an essay for extra credit when they were provided a list of only 6 , rather than 30 , potential essay topics. Moreover, even after having chosen to write an essay, students wrote higher quality essays if their essay topic had been picked from a smaller rather than a larger choice set. Finally, Study 3 demonstrated that people reported enjoying the process of choosing a chocolate more from a display of 30 than from a display of 6 . However, despite their greater initial enjoyment in the extensive-display condition, participants proved more dissatisfied and regretful of the choices they made and were subsequently considerably less likely to choose chocolates rather than money as compensation for their participation.

But, what are the mediating mechanisms underlying this phenomenon of choice overload? Contrary to the predictions of our first hypothesis, we found no empirical support in Study 3 for the theory that choosers in extensive-choice contexts are more likely to use a satisficing heuristic, whereas choosers in a limited-choice context are more likely to use an optimizing heuristic. Instead, at least in this study, choosers in both extensive-choice contexts and limited-choice contexts tended to report using a satisficing heuristic. Nor were there any differences in participants' reports of their anticipated satisfaction with the selections they had made, their feelings of having made an informed choice, or their tendency to opt for a default choice.

Consistent with our second hypothesis, however, we did find considerable empirical support for the theory that choosers in extensive-choice contexts enjoy the choice-making process more-presumably because of the opportunities it affords-but also feel more responsible for the choices they make, resulting in frustration with the choice-making process and dissatisfaction with their choices. Indeed, participants in the extensive-choice condition reported experiencing the decision-making process as being simultaneously more enjoyable, more difficult, and more frustrating. Later, after actually sampling their chocolates, extensivechoice participants reported being more dissatisfied and having more regret about the choices they had made than did limitedchoice participants. This greater dissatisfaction and regret exhibited by extensive-choice participants may be the consequence of an initial greater tendency to disengage from the choice-making process, which later results in the choosers' inability to use the psychological processes for the enhancement of the attractiveness of their own choices (see Gilovich \& Medvec, 1995). Even more compelling, participants in the extensive-choice condition were actually less likely to opt for chocolates rather than money as their compensation than were their limited-choice counterparts, and they did not differ in this respect from participants in the no-choice control condition.

How can there be so much dissatisfaction in the face of so much opportunity? More than providing a conclusive answer to this question, the present findings raise a number of questions of both theoretical and practical relevance that are worth considering in future research. 
Perhaps it is not that people are made unhappy by the decisions they make in the face of abundant options but that they are instead unsure-that they are burdened by the responsibility of distinguishing good from bad decisions. Interviews with several hundred U.S. citizens suggest that modern Americans are uneasy about their current life decisions-that they do not seem to know whether they are doing the right things with their lives, or even what those "right things" are (Bellah, Madsen, Sullivan, Swindler \& Tipton, 1985). Our findings demonstrate that the offer of overly extensive choices in relatively trivial choice-making contexts can have significant demotivating effects, but perhaps the phenomenon of choice overload may be further exacerbated in contexts (such as decisions about major stock purchases or alternative medical treatments) in which (a) the costs associated with making the "wrong" choice, or even beliefs that there are truly "wrong" choices, are much more prominent, and/or (b) substantial time and effort would be required for choosers to make truly informed comparisons among alternatives. In the present studies, care was taken to select tasks for which "right" and "wrong" choices would be subjective and for which the effort involved in making a choice would be largely a function of personal preferences. If one were to compare the present contexts to those in which the choosers perceived there to be significantly "better" and "worse" choices, in domains of personal significance, we might expect even more substantial choice overload effects.

Indeed, whether choosers perceive their choice-making task to be a search for the "objectively best" option, or a search for the one option most reflective of their personal preferences, may fundamentally influence their very preference for choosing. Although prior research has indicated that people will necessarily be intrinsically motivated to make their own choices, the more choosers perceive their choice-making task to necessitate expert information, the more they may be inclined not to choose, and further, they may even surrender the choice to someone else-presumably more expert (e.g., de Charms, 1968; Deci \& Ryan, 1985; Langer \& Rodin, 1976; Lepper, 1983; Malone \& Lepper, 1987; Schulz, 1976; Taylor, 1989; Zuckerman et al., 1978). In Schwartz's (1994) terms, one important paradox confronting the modern world is that as the freedom of individuals expands, so too does their dependence on institutions and other people.

Similarly, if the identity of the choice recipient were varied, we might observe variation in the experience of choice overload among the choosers. Prior research has shown that, when confronted by choices that are anticipated to result in regret, choosers experience decision aversion more so when making choices for others-even when the others exhibit no preferences-than when making choices for themselves (Beattie, Baron, Hershey, \& Spranca, 1994). In the three present studies, we did not systematically vary the identity of the choice recipients. Consistent with the results of Beattie and his colleagues, we might expect that if we were to compare choosers making choices for themselves with choosers making choices for others, the latter would show greater choice overload effects in extensive-choice contexts.

Perhaps the experience of choice overload is accompanied by the use of more decision rules, which are affective rather than cognitive. Contrary to recent findings by Dhar and Nowlis (1999), the results from our studies suggest that even when a choice- making situation involves an approach-approach conflict, the provision of choices with uniquely good features does not appear to minimize decision aversion. Being confronted by a plethora of options, each possessing unique attributes, may instead simultaneously attract and repel choice-makers. One wonders then: Do people use affective experiences aroused by choosing as a heuristic for deciding how they ultimately feel about the product? If not such an affective "bleedover," then what else might be accounting for these effects?

Moreover, even when choices are self-generated, it is possible that overly extensive choices may have demotivating consequences. Because people seem to enjoy extensive-choice contexts more than limited-choice contexts, they may sometimes prefer to make available to themselves many more choices than they can possibly handle. Hence, it would be of considerable theoretical interest to examine the effects of extensive-choice contexts that are self-generated, rather than externally generated as in the present studies.

Finally, it is worth considering attributes of contexts in which the provision of extensive choices does not lead to choice overload. To minimize the likelihood of simple preference-matching in the present studies, we selected specific choice-making tasks and prescreened our participant population to ensure that they would not already have strong specific preferences. We all know people who, when confronted by an extraordinary variety of options, know exactly what they want. Is this certainty in preference the result of arduously developed and maintained expertise? The ultimate paradox might be that the only circumstance in which choosers are truly comfortable with extensive choices is when, because of the chooser's previous experience, these choices are perceived as limited in number. Therefore, the precise number of options that would be considered reasonable, as opposed to excessive, may vary as a function of both the chooser's perception of their choicemaking goals and their prior expertise with the subject of choice.

Having unlimited options, then, can lead people to be more dissatisfied with the choices they make. Although such a finding may seem counterintuitive to social psychologists long schooled in research on the benefits of choice, the commercial world seems already to know what experimental psychologists are just now discovering. Several major manufacturers of a variety of consumer products have been streamlining the number of options they provide customers. Proctor \& Gamble, for example, reduced the number of versions of its popular Head and Shoulders shampoo from 26 to 15 , and they, in turn, experienced a $10 \%$ increase in sales (Osnos, 1997). Indeed, even to many of today's humorists, this phenomenon seems already well known. Consider Bill Watterson's (1996) portrayal of one particularly exasperated grocery shopper:

Look at this peanut butter! There must be three sizes of five brands of four consistencies! Who demands this much choice? I know! I'll quit my job and devote my life to choosing peanut butter! Is "chunky" chunky enough or do I need EXTRA chunky? I'll compare ingredients! I'll compare brands! I'll compare sizes and prices! Maybe I'll drive around and see what other stores have! So much selection, and so little time! (p. 107) 


\section{References}

Beattie, J., Baron, J., Hershey, J. C., \& Spranca, M. D. (1994). Psychological determinants of decision attitude. Journal of Behavioral Decision Making, 7, 129-144.

Bellah, R., Madsen, R., Sullivan, W., Swindler, A., \& Tipton, S. (1985). Habits of the heart. Los Angeles: University of California Press.

Bovie, P. (Ed.) (1992). Terence: The comedies. Baltimore and London: Johns Hopkins University Press.

Brehm, J. W. (1966). A theory of psychological reactance. New York: Academic Press.

Christensen-Szalanski, J. J. J. (1978). Problem solving strategies: A selection mechanism, some implications, and some data. Organizational Behavior and Human Performance, 22, 307-323.

Christensen-Szalanski, J. J. J. (1980). A further examination of the selection of problem-solving strategies: The effects of deadlines and analytic aptitudes. Organizational Behavior and Human Performance, 25, 107122

Collins, B. E., \& Hoyt, M. G. (1972). Personal responsibility for consequences: An integration and extension of the "forced compliance" literature. Journal of Experimental Social Psychology, 8, 558-593.

Cooper, J., \& Fazio, R. H. (1984). A new look at dissonance theory. In L. Berkowitz (Ed.), Advances in experimental social psychology (Vol. 17, pp. 229-266). Orlando, FL: Academic Press.

Cordova, D. I., \& Lepper, M. R. (1996). Intrinsic motivation and the process of learning: Beneficial effects of contextualization, personalization, and choice. Journal of Educational Psychology, 88, 715-730.

de Charms, R. (1968). Personal causation. New York: Academic Press.

Deci, E. L. (1975). Intrinsic motivation. New York: Plenum Press.

Deci, E. L. (1981). The psychology of self-determination. Lexington, MA: Heath.

Deci, E. L., \& Ryan, R. M. (1985). Intrinsic motivation and selfdetermination in human behavior. New York: Plenum Press.

Delucchi, K. L. (1983). The use and misuse of chi-square: Lewis and Burke revisited. Psychological Bulletin, 94, 166-176.

Dember, W. N., Galinsky, T. L., \& Warm, J. S. (1992). The role of choice in vigilance performance. Bulletin of the Psychonomic Society, 30, 201-204.

de Tocqueville, A. (1969). Democracy in America. New York: Harper \& Row. (Original work published in 1830)

Dhar, R. (1997). Consumer preference for a no-choice option. Journal of Consumer Research, 24, 215-231.

Dhar, R., \& Nowlis, S. (1999). The effect of time pressure on consumer choice deferral. Journal of Consumer Research, 25, 369-384.

Gilovich, T., \& Medvec, V. H. (1995). The experience of regret: What, when, and why. Psychological Review, 102, 379-395.

Glass, D. C., \& Singer, J. E. (1972a). Stress and adaptation: Experimental studies of behavioral effects of exposure to aversive events. New York: Academic Press.

Glass, D. C., \& Singer, J. E. (1972b). Urban stress. New York: Academic Press.

Hauser, J. R., \& Wernerfelt, B. (1990). An evaluation cost model of consideration sets. Journal of Consumer Research, 16, 393-408.

Hendrick, C., Mills, M., \& Kiesler, C. A. (1968). Decision time as a function of the number and complexity of equally attractive alternatives. Journal of Personality and Social Psychology, 8, 313-318.

Kelley, H. H. (1967). Attribution theory in social psychology. In D. Levine (Ed.), Nebraska Symposium on Motivation (Vol. 15, pp. 192-240). Lincoln, NE: University of Nebraska Press.

Kelley, H. H. (1973). The process of causal attribution. American Psychologist, 28, 107-128.

Kiesler, C. A. (1966). Conflict and number of choice alternatives. Psychological Reports, 18, 603-610.
Langer, E. J. (1975). The illusion of control. Journal of Personality and Social Psychology, 32, 311-328.

Langer, E. J., \& Rodin, J. (1976). The effects of choice and enhanced personal responsibility for the aged: A field experiment in an institutional setting. Journal of Personality and Social Psychology, 34, 191198

Lefcourt, H. M. (1973). The function of the illusions of control and freedom. American Psychologist, 28, 417-425.

Lepper, M. R. (1983). Social control processes and the internalization of social values: An attributional perspective. In E. T. Higgins, D. N. Ruble, \& W. W. Hartup (Eds.), Social cognition and social development (pp. 294-330). New York: Cambridge University Press.

Lewin, K. (1952). Group decision and social change. In G. E. Swanson, T. M. Newcomb, \& E. L. Hartley (Eds.), Readings in social psychology (pp. 459-473). New York: Henry Holt

Linder, D. E., Cooper, J., \& Jones, E. E. (1967). Decision freedom as a determinant of the role of incentive magnitude in attitude change. Journal of Personality and Social Psychology, 6, 245-254.

Malone, T. W., \& Lepper, M. R. (1987). Making learning fun: A taxonomy of intrinsic motivations for learning. In R. E. Snow \& M. J. Farr (Eds.), Aptitude, learning and instruction: Vol. 3. Cognitive and affective process analysis (pp. 223-253). Hillsdale, NJ: Erlbaum.

Mills, J., Meltzer, R., \& Clark, M. (1977). Effect of number of options on recall of information supporting different decision strategies. Personality and Social Psychology Bulletin, 3, 213-218.

Osnos, E. (1997, September 27). Too many choices? Firms cut back on new products. Philadelphia Inquirer, D1, D7.

Payne, J. (1982). Contingent decision behavior. Psychological Bulletin, 92, 382-402.

Payne, J. W., Bettman, J. R., \& Johnson, E. J. (1988). Adaptive strategy selection in decision making. Journal of Experimental Psychology: Learning, Memory, and Cognition, 14, 534-552.

Payne, J. W., Bettman, J. R., \& Johnson, E. J. (1993). The adaptive decision maker. Cambridge, MA: Cambridge University Press.

Rotter, J. B. (1966). Generalized expectancies for internal versus external locus of control of reinforcement. Psychological Monographs, 80, 1-28.

Schulz, R. (1976). Effects of control and predictability on the physical and psychological well-being of the institutionalized aged. Journal of Personality and Social Psychology, 33, 563-573.

Schulz, R., \& Hanusa, B. H. (1978). Long-term effects of control and predictability-enhancing interventions: Findings and ethical issues. Joumal of Personality and Social Psychology, 36, 1194-1201.

Schwartz, B. (1994). The casts of living: How market freedom erodes the best things in life. New York: W. W. Norton \& Company.

Schwartz, B. (2000). Self-determination: The tyranny of freedom. American Psychologist, 55, 79-88.

Shafir, E., Simonson, I., \& Tversky, A. (1993). Reason-based choice. Cognition, 49, 11-36.

Shafir, E., \& Tversky, A. (1992). Thinking through uncertainty: Nonconsequential reasoning and choice. Cognitive Psychology, 24, 449474.

Siegel, S. (1956). Nonparametric statistics for the behavioral sciences. New York: McGraw-Hill.

Simon, H. A. (1955). A behavioral model of rational choice. Quarterly Journal of Economics, 59, 99-118.

Simon, H. A. (1956). Rational choice and the structure of the environment. Psychological Review, 63, 129-138.

Swann, W. B., \& Pittman, T. S. (1977). Initiating play activity of children: The moderating influence of verbal cues on intrinsic motivation. Child Development, 48, 1128-1132.

Taylor, S. E. (1989). Positive illusions: Creative self-deception and the healthy mind. New York: Basic Books.

Taylor, S. E., \& Brown, J. D. (1988). Illusion and well-being: A social- 
psychological perspective on mental health. Psychological Bulletin, 103, 193-210.

Timmermans, D. (1993). The impact of task complexity on information use in multi-attribute decision making. Journal of Behavioral Decision Making, 6, 95-111.

Watterson, B. (1996). It's a magical world. Kansas City: Andrews and McMeel.

Wright, P. (1975). Consumer choice strategies: Simplifying vs. optimizing. Journal of Marketing Research, 12, 60-67.
Zuckerman, M., Porac, J., Lathin, D., Smith, R., \& Deci, E. L. (1978). On the importance of self-determination for intrinsically motivated behavior. Personality and Social Psychology Bulletin, 4, 443-446.

Received January 24, 2000

Revision received June 16, 2000

Accepted June 19, 2000 